\title{
A CONTRIBUIÇÃO DA ANTROPOLOGIA FILOSÓFICA DE EDITH STEIN NA DISCUSSÃO SOBRE A FORMAÇÃO FILOSÓFICA E PEDAGÓGICA DO PROFESSOR DE FILOSOFIA
}

\author{
EDITH STEIN'S PHILOSOPHYCAL ANTHROPOLOGY \\ CONTRIBUTION TO THE DISCUSSION ABOUT THE \\ PHILOSOPHYCAL AND PEDAGOGICAL EDUCATION OF THE \\ PHILOSOPHY TEACHERS
}

\author{
Sônia Maria Lira Ferreira ${ }^{1}$ \\ Walter Matias Lima ${ }^{2}$
}

Recebido em: 05/2018

Aprovado em: 07/2018

\begin{abstract}
Resumo: O presente artigo tem como tema norteador a formação docente na área de filosofia e dos seus reflexos na prática docente nas escolas do Ensino Médio investigado à luz da perspectiva antropológica e pedagógica da filosofia de Edith Stein. O objetivo principal é apresentar os conceitos principais da Antropologia Filosófica- Teológica e da Pedagogia de Edith Stein enquanto um aporte teórico que possibilita problematizar a discussão sobre a formação docente na área de Filosofia em seus aspectos filosóficos e pedagógicos no contexto atual da crise instalada na educação brasileira. Este estudo utilizou procedimentos bibliográficos fundamentados no pensamento filosófico e pedagógico de Stein, Edith (2003); ALFIERI, Francesco (2014); SBERGA, Adair Aparecida (2014); RUS, Éric de (2015); TOMAZETTI, Elisete Medianeira et.al.(2012); MATTÉI, Jean- François (2002); KUSANO, Mariana Bar (2014). O procedimento metodológico utilizado para a elaboração do texto foi o fenomenológico por descrever a experiência do homem tal como ela é. A questão norteadora que fundamentou os argumentos desse artigo foi a seguinte: Como os conceitos antropológicos e pedagógicos do pensamento filosófico de Edith Stein, podem contribuir para se pensar no âmbito acadêmico uma nova estruturação da formação filosófica e pedagógica dos professores de filosofia? E, para responder essa questão, a explanação dos argumentos foi estruturada a partir dos seguintes passos: primeiro passo se fez uma introdução do tema-problema com seus objetivos, problema e metodologia; segundo passo, foi apresentado o caminho filosófico e metodológico da estruturação da antropologia filosófica e teológica como também da pedagogia de Edith Stein; terceiro passo consistiu na explanação dos conceitos de: corpo, psique e espírito; quarto passo foi demonstrado como os conceitos filosóficos e pedagógicos de Edith Stein podem ser uma ferramenta eficaz para se pensar criticamente a formação docente na área de filosofia e do seu ensino mediante novos horizontes formativos.

Palavras-chave: Formação docente em filosofia; ensino de filosofia; antropologia e pedagogia de Edith Stein.
\end{abstract}

\footnotetext{
1 Aluna do Doutorado em Educação - PPGE/CEDU/UFAL- Vinculada a Linha de Pesquisa: Processos Educativos- do Grupo de Pesquisa Filosofia e Educação e Ensino de Filosofia da UFAL. Orientanda do Prof. Dr $^{\circ}$. Walter Matias Lima. Professora da Universidade Federal de Campina Grande- UFCG - Centro de Educação do Semiarido- CDSA/SUMÉ. E-MAIL: sonialira.filosofia@gmail.com

2 Doutor em Educação- Professor do PPGE/CEDU/UFAL (Doutorado e Mestrado) Vinculado a Linha de Pesquisa: Processos Educativos- Líder do Grupo de Pesquisa Filosofia e Educação e Ensino de Filosofia da UFAL. Professor da Universidade Federal de Alagoas. E-mail: waltermatias@gmail.com
} 


\begin{abstract}
The current work has as a guiding subject the teachers education in the philosophy area and its reflexes in the teaching practice in High School researched according to Edith Stein's anthropological and pedagogical perspective. The principal objective is to present the theological and philosophycal anthropology and Edith Stein's pedagogy main concepts as a theoretical subsidy which allows to discuss the matter about teaching education in the philosophy area in its pedagogical and philosophycal aspects in the current context of the Brazilian educational crisis. This work has used bibliographical procedures based on the pedagogical and philosophycal work of STEIN, Edith (2003); ALFIERI, Francesco (2014); SBERGA, Adair Aparecida (2014); RUS, Éric de (2015); TPMAZETTI, Elisete Medianeira et al. (2012); MATTEI, Jean-François (2002); KUSANO, Mariana Bar (2014). The methodological procedure used to the work elaboration has been the phenomenological one once it describes the human being experience properly. The guiding subject which has founded this work has been the following one: how the pedagogical and anthropological concepts of Edith Stein's philosophycal work can contribute to think about a new structuring of the pedagogical and philosophycal education of the philosophy teachers in the academic context? In order to answer this question it has been necessary to take some steps: the first one has been an introduction of the subject and its aims and methodology; the second one has been a presentation of the methodological and philosophycal way of Edith Stein's anthropological and theological structuring and her pedagogy as well; the third one has been the explanation of the concepts of body, psyche and soul; the fourth one has been the demonstration of how Edith Stein's pedagogical and philosophycal concepts can be an efficient tool to think pointedly about the teaching education in the philosophy area and its teaching by means of new educational horizons.

Key-words: philosophy teachers education; philosophy teaching; Edith Stein's philosophy and pedagogy.
\end{abstract}

\title{
Introdução
}

O escopo do estudo investigativo que resultou na fomentação desse trabalho acadêmico, ainda de caráter parcial, faz parte de uma pesquisa em andamento de doutorado do Programa de Pós-Graduação em Educação, da Universidade Federal de Alagoas- do Centro de Educação- PPGE/CEDU/UFAL, que tem como objetivo principal demonstrar a relevância da antropologia filosófica e da perspectiva pedagógica de Edith Stein enquanto uma ferramenta teórica para se pensar na contemporaneidade, o percurso da formação filosófica e pedagógica do professor de filosofia no âmbito acadêmico e dos seus reflexos no ensino de filosofia nas escolas do Ensino Médio. O tema-problema norteador do desenvolvimento no texto pode ser vislumbrado pelos seguintes questionamentos: Quais são os conceitos antropológicos e pedagógicos constituídos no âmbito da filosofia de Edith Stein? E, de que forma, esses conceitos antropológicos e pedagógicos do seu pensamento filosófico podem contribuir para se pensar no âmbito acadêmico a estruturação da formação filosófica e pedagógica dos professores de filosofia? E como se pode estabelecer a relação dessa reflexão com o ensino de filosofia nas escolas? Para o desenvolvimento do tema-problema a partir das questões colocadas, foi delimitada uma pesquisa bibliográfica e alicerçada no método fenomenológico. A escolha desse método para o desenvolvimento do tema-problema delimitado se justifica, 
porque é o que melhor se aproxima do mundo vivido, a fenomenologia descreve a experiência do homem tal como ela é. A escolha pelo pensamento filosófico de Edith Stein se considera pertinente, por ter elegido a dignidade humana e a vivência da liberdade como uma preocupação primordial para estruturação do mundo humano e da convivência humanizada no mundo. Estes são os elementos considerados por Stein como constitutivos da comunidade humana livre de qualquer traço de barbárie no processo de sua formação educativa. Com o objetivo de apresentar a arguição sistemática do tema proposto nesse texto acadêmico, tornouse imprescindível apresentar, inicialmente, alguns conceitos da antropologia filosófica e teológica de Edith Stein que, certamente, possibilitou, em seguida, apontar as pistas teóricas na discussão sobre a formação acadêmica do professor de filosofia e dos seus reflexos no ensino de filosofia das escolas do Ensino Médio.

\section{Conceitos basilares da antropologia (filosófica e teológica) de Edith Stein: a constituição do ser humano na sua dimensão corpo, psique e espírito}

Edith Stein ao estruturar o seu curso A Estrutura da Pessoa Humana, escrito no inverno dos anos 1932 e 1933, desenvolve a tese de que toda prática educativa deverá se alicerçar numa ideia de homem enquanto uma linha norteadora na construção significativa da prática docente, pois irá considerar a compreensão do mundo de cada individuo no seu processo de formação.

Todo labor educativa que trate de formar hombres va acompañada de uma determinada concpción del hombre, de quáles son sua posición en el mundo y su misión en la vida, y de qué possibilidades prácticas se ofrecen de tratar y formar al hombre (STEIN, 2003, p. 562).

Stein, na afirmação acima, deixa claro que o tema central de suas investigações filosóficas é o ser humano e, dessa forma, assumiu a missão pela busca dos fundamentos antropológico-filosóficos para fundamentar tanto a sua teoria quanto a sua prática docente. Essa busca pelos fundamentos antropológico-filosóficos foi desenvolvida mediante o método fenomenológico que, segundo Sberga, possibilitou Stein elaborar as seguintes questões:

[...] quem é o ser humano? Como se constituiu? Qual é a sua especificidade em relação aos outros seres? Questões fundamentais sobre a existência humana, que vão além da física e das coisas particulares, remetendo aos estudos de filosofia, especialmente da área da antropologia filosófica 
(SBERGA, 2014, p.137).

As questões acima ressaltadas foram as que possibilitaram Edith Stein elaborar a sua concepção de ser humano alicerçada no estudo sobre a corporeidade. Esse estudo apresenta três dimensões que, juntas, compõem a estrutura do ser humano, a saber: o corpo, a psique e o espírito. Dessa forma, o que torna todo ser humano igual entre si é o fato incontestável de que a sua natureza é formada por um corpo, por uma psique e por um espirito. É relevante esclarecer que a análise dessas três dimensões da natureza humana separadamente, no pensamento filosófico de Stein, é decorrente de uma abstração, pois é perceptível que a filósofa demonstra nas suas argumentações desenvolvidas no interior da sua obra A Estrutura da Pessoa Humana que existe uma relação essencial e necessária entre o corpo, a alma e o espirito. A abstração serve, nesse caso, como um recurso do pensamento para elaborar uma descrição do que é pertinente e essencial a cada uma das três dimensões da natureza humana e estudá-las. Segundo Edith Stein é relevante, porque possibilita o desenvolvimento da formação humana em bases sólidas. Estas últimas podem ser vislumbradas e constituídas através da investigação sobre o conhecimento da estrutura do ser em questão: o ser humano. Stein demonstra nas suas argumentações filosóficas que todo processo formativo deverá ter como alicerce tão somente o conhecimento total do ser humano. Esse conhecimento impeliu, segundo Sberga (2014, p.105), Stein a refletir, a seguinte questão: “[...] como se constitui a pessoa humana?" Seguindo o itinerário de Edith Stein serão abordados os conceitos de corpo, psique e espírito e, por último, serão apresentadas as pistas com o caráter tão somente de sugestões de como a formação filosófica e pedagógica do professor de filosofia poderá ser pensada e vivenciada no âmbito acadêmico à luz dos conceitos da antropologia filosófica e teológica e da pedagogia de Edith Stein e, com isso, serão apresentados os reflexos dessas pistas no ensino de filosofia que acontece no chão da escola.

\section{O caminho filosófico e metodológico da estruturação da pessoa humana no pensamento de Edith Stein}

Para se pensar como a filósofa Edith Stein apresenta o processo de constituição da pessoa humana, é pertinente atentar para tese que move o seu pensamento filosófico, a saber: a de que no ato de se pensar essa constituição não se pode prescindir da ideia de que o ser humano não pode ser pensado conceitualmente dissociado do todo que ele é como também da 
sua composição. Dessa forma, Stein se volta para pensar a realidade constitutiva do ser humano mediante três dimensões, como já foi citado anteriormente, enquanto: corpo, alma e espírito. Edith Stein com o objetivo de responder a questão: Quem é o ser humano? na sua obra A Estrutura da Pessoa Humana, aponta os vieses da sua argumentação ao investigar qual seria a Antropologia que possibilitaria pela via da filosofia e da teologia fundamentar a Pedagogia e a Educação em bases seguras e consistentes para que possam atingir a compreensão das estruturas que compõem o ser humano em sua individualidade e totalidade. $\mathrm{O}$ seu ponto de partida na busca investigativa dessa Antropologia para fundamentar a Pedagogia e a Educação, consistiu, incialmente, na apresentação crítica das características teóricas e metodológicas da antropologia alicerçada tanto nas ciências da natureza quanto nas ciências humanas com o objetivo de demonstrar as suas limitações e fragilidades e também o que é meritório no que concerne à compreensão da ser humano, pois a sua preocupação é demonstrar as limitações teóricas e metodológicas dessas visões antropológicas que não as impelem perceber o ser humano por inteiro e, dessa forma, desfavorecem a prática educativa, como também, perceber dentre essas visões antropológicas do ser humana cunhadas no transcorrer da história humana, as que favorecem de forma positiva a prática educativa e a formação humana. Stein justifica a relevância dessa busca investigativa pelas as razões desenvolvidas na sua obra A Estrutura da Pessoa Humana comentadas a seguir.

Na primeira razão, a autora afirma que a Antropologia alicerçada na ciência natural tem como escopo investigativo apresentar, a partir da teoria da evolução, o homem como uma espécie de animal mais evoluído e, mediante essa ideia, procurou diferenciar a estrutura e as funções do corpo humano em relação às estruturas do corpo do animal; segundo, fez uma descrição da imagem do homem pela via empírica mediante a observação e descrição e, ao ter essa imagem do homem como referência, se propõe investigar as diferenças que existem dentro da unidade dessa imagem. Para atingir essas diferenças com clareza, esse tipo de Antropologia se vê na incumbência de estabelecer uma série de tipos morfológicos, justamente por buscar as causas dessas diferenças, a delimitação das raças, tribos e povos. Nesse momento, a sua investigação passa da perspectiva morfológica para o histórico e evolutivo e, assim, o seu foco a partir daí será pesquisar as leis universais que alicerçam a evolução do individuo, dos estágios em que se encontra da sua hereditariedade, da idade cronológica do seu surgimento na terra e as características que diferenciam os homens de épocas diferentes. E, ao proceder dessa forma, o que se pretende de fato é fixar a sequência evolutiva do ser humano e, também, determinar as leis que regem essa evolução. Se pode 
afirmar, de acordo com o pensamento de Edith Stein que a Antropologia com as características de uma ciência natural se limita a uma explicação da constituição da natureza humana pela via morfológico-descritiva, e causal-explicativa e, certamente, não leva em consideração o fato de que o ser humano além do corpo, visto tão somente com um exemplar da espécie, tem psique e espirito. A noção de exemplar no contexto dessa Antropologia desemboca numa fratura do ser humano na medida em que a sua perspectiva é meramente demarcada por leis universais que não contemplam no seu âmbito a dimensão individual do ser humano. Por isso, é relevante perceber a crítica e o alerta que faz Stein de que o ser humano não se resume estritamente a sua dimensão biológica. Eis, os argumentos principais apresentados por Stein acerca da limitação teórica e metodológica desse tipo de Antropologia:

Dado que la formación y la educación han de abarcar al hombre entero, tanto a su cuerpo como a su alma, es importante para el educador conocer la estructura, las funciones y las leyes evolutivas del cuerpo humano. Sólo así podrá saber qué puede fomentar su desarrollo natural y qué puede perjudicarlo. Es asimismo importante conocer las leyes generales de la vida anímica del hombre, a fin de tenerlas en cuenta en la labor educativa (STEIN, 2003, p. 580).

Segunda, ao apresentar os argumentos do fracasso da Antropologia da Ciência Natural enquanto fundamento da Pedagogia e da Educação devido ao fato de estudar o ser humano como um exemplar e, dessa forma, se limitar a uma perspectiva abstrata da natureza do ser humano, Stein continua a sua investigação impelida pela certeza que poderá fundamentar uma Antropologia que contemple o ser humano concreto. A filósofa defende a ideia de que a Pedagogia e a Educação não poderão, então, se limitar a uma perspectiva abstrata da natureza do ser humano. Essa perspectiva abstrata ocorre quando as investigações antropológicas se voltam estritamente para a sua dimensão universal e, dessa forma, não contemplam no seu escopo a compreensão da individualidade do ser humano. Essas argumentações possibilitaram Stein a levantar as seguintes questões: “[...] ¿existe una antropologia que cumpla esos requisitos? De entrada: ¿hay una antropologia que pueda ayudamos a comprender la individualidad? Y como pregunta previa a ésta: ¿existen ciencias que tengan por objeto al individuo en su individualidad?" (STEIN, 2003, p. 581).

As perguntas acima refletem a percepção de que a busca de Edith Stein deverá avançar nas suas investigações para o âmbito das ciências humanas. Nesse sentido, é notório que analise de forma crítica os passos dados por essas ciências na constituição do conceito de ser humano com o objetivo de saber se as mesmas podem contribuir de forma significativa, para 
que os educadores e as educadoras na sua prática docente venham a atingir a compreensão de como são constituídos os seres humanos com os quais mantêm uma relação intersubjetiva no processo educativo, ou seja, seus educandos. Edith Stein defende a ideia de que a compreensão da constituição do ser humano em sua universalidade e individualidade é o que vai proporcionar aos educadores e educadoras as condições bem fundamentadas de uma prática educativa que possibilitará uma formação humana que promova de acordo com Sberga (2014, p. 156) "[...] o desenvolvimento das dimensões da estrutura da pessoa, que são universais e, portanto, da condição dos seres humanos," e, dessa forma, “[...] cada ser se desenvolve segundo a sua originalidade, suas tendências e dons pessoais".

Para atingir o objetivo de sua busca investigativa, Stein perscruta o caminho teórico e metodológico das ciências humanas no tratamento dado ao problema da constituição do ser humano. No decorrer do processo dessa investigação, verifica que a antropologia alicerçada no viés das ciências humanas se diferencia da antropologia fundamentada no viés das ciências naturais e, para ratificar a tese de Stein, se tomou a sua apreciação e diferenciação que fez ao comentar sobre a História, que como uma das ciências humanísticas, que trata de algo único e não universal: “[...] Existen ciencias humanísticas que se ocupan de algo único: la historia trata de investigar y exponer la marcha de la humanidad a lo largo del tiempo, tal y como ha tenido lugar de modo único e irrepetible, en individuos humanos y en pueblos concretos" (STEIN, 2003, p. 582).

A História, de acordo com Stein, mostra a importância de apreensão do individuo na sua dimensão concreta, sua história de vida enquanto um ser individual e a sua trajetória no tempo e tem como objetivo fazer uma exposição dessa individualidade do ser humano de forma que seja compreensível para todos. Edith Stein toma esse exemplo da História como uma das ciências humanas, porque a possibilita a investigar se essa antropologia atrelada às ciências humanas possa: “[...] comprobar si pueden ayudar al educador a compreender a los indivíduos de los que se ocupa" (STEIN, 2003, p. 582). E, devido a essa necessidade de compreensão é que Edith Stein problematiza acerca se essa antropologia que se liga às ciências humanas mantém ou não uma relação com a filosofia, pois essa relação entre a antropologia e a filosofia é justamente a que poderá fundamentar uma investigação filosófica acerca da compreensão do ser que investiga: o ser humano. Mediante o exposto, afirma que a Antropologia que busca para ser o fundamento da Pedagogia terá que: 
conjunto de la problemática filosófica, la estructura del hombre y su inserción en las distintas modalidades y territorios del ser a los que pertenece. También habrá de ocuparse de averiguar la causa de que dos ciencias empíricas -la antropología concebida como una ciencia de la naturaleza y la que se entiende a sí misma como una ciencia humanísticaestudien al hombre con métodos totalmente diferentes. El sentido y la justificación de este modo de proceder habrán de buscarse en la pertenencia del hombre a los diferentes ámbitos del ser a los que damos los nombres de "naturaleza" y "espíritu" (STEIN, 2003, p. 587).

A definição acima traz à tona um âmbito do ser que não é discutido pela antropologia filosófica que é o espiritual. Por corroborar essa ideia desenvolvida anteriormente, é pertinente atentar para a observação de kusano (2014, p. 69) sobre a natureza humana: "Para Stein, a natureza humana participa tanto do reino do espírito quanto do reino da natureza". O objetivo de Stein é esclarecer de forma contundente o limiar entre os dois âmbitos do ser: o natural e o espiritual e, também, demonstrar como esses dois âmbitos se relacionam e como ambos influenciam na interioridade do ser humano. A dimensão espiritual da natureza humana é tratada por Edith Stein como aquela que possibilita a percepção que o ser humano por ser finito e se encontrar entre outros seres humanos também finitos, não alcança a compreensão total de si mesmo. Essa impossibilidade do ser humano de compreender a si mesmo de forma completa é percebida através do desenvolvimento da antropologia filosófica por revelar a sua limitação em atingir o sentido pleno da dimensão espiritual do ser humano pelas seguintes razões ressaltadas por Stein em A Estrutura da Pessoa Humana:

Temos intentado responder a esta pregunta: ¿qué es el hombre? Hemos artido de la experiencia, en la que se nos dan hombres. Hemosanalizado el contenido de esa experiencia, para dejar a un lado lo con- tingente y subrayar lo sencial. Esta es una reflexión filosófica, y dado que aspira a comprender la estructura esencial de un ser, denominamos a este procedimiento ontológico. Entre las eculiaridades del ser del que nos estamos ocupando se cuenta la de que es finito. Es característico de todo finito el hecho de que no puede ser comprendido exclusivamente por sí mismo, sino que remite a un primer ser que hemos de considerar infinito, o, más correctamente, al ser infinito, porque el ser infinito sólo puede ser Uno. A este ser primero e infinito le damos el nombre de Dios, dado que sus atributos están en correspondencia con nuestra idea de Dios. De esta manera, se puede considerar como un conocimiento ontológico el de que el ser del hombre, al igual que todo lo finito, remite a Dios y sin relación con el ser de Dios sería incomprensible: incomprensible tanto que sea (su existencia) como que sea lo que es (STEIN, 2003, p. 741-742).

Os argumentos de Stein sobre a importância da antropologia teológica para fundamentar o processo educativo do ser humano recaí justamente na limitação apresentada 
pela antropologia filosófica por não ter condições no seu escopo de dar respostas a algumas perguntas tais como: a origem do mundo, do gênero humano, dos indivíduos humanos. Para essas questões, Stein afirma que só podem ser respondidas pela via da Revelação, pois as verdades reveladas é uma base segura para a vida humana. Essas verdades reveladas, ou seja, verdades da fé, certamente, conseguem dar a resposta acerca da pergunta sobre a origem do ser humano enquanto uma criação divida, assim, revela que o ser humano foi criado segundo a vontade de Deus. Também revela que toda a comunidade se origina e tem a sua razão de ser em Deus, que o ser humano é imagem e semelhança de Deus, que o ser humano é livre e, sobretudo, que o ser humano deve fazer que sua vontade esteja em consonância com a vontade de Deus. O desenvolvimento tanto da antropologia filosófica quanto da teológica em Edith Stein só poderá ser desenvolvida mediante a sua escolha metodológica: “[...]Por lo tanto, nuestro camino será el sistemático: tendremos que fijar nuestra atención en las cosas mismas e ir construyendo sobre esa base en la medida en que podamos. Para ello, naturalmente, hemos de proceder con arreglo a un método determinado" (STEIN, 2003, p. 590).

A terceira razão se refere à escolha do método que Stein determinou para solucionar os seus problemas filosóficos, o fenomenológico. O método fenomenológico foi elaborado e aplicado pelo filósofo Edmund Husserl pela primeira vez, no seu livro do segundo volume da sua obra Investigações lógicas: sexta investigação - elementos de uma investigação logica do conhecimento. Stein afirma que esse método é o único capaz de proporcionar uma análise qualitativa do ser humano.

[...] el principio más elemental del método fenomenológico: fijar nuestra atención en las cosas mismas. No interrogar a teorías sobre las cosas, dejar fuera en cuanto sea posible lo que se há oído y leído y las composiciones de lugar que uno mismo se ha hecho, para, más bien, acercarse a las cosas con una mirada libre de prejuicios y beber de la intuición inmediata. Si queremos saber qué es el hombre, tenemos que ponemos del modo más vivo posible en la situación en la que experimentamos la existencia humana, es decir, lo que de ella experimentamos en nosotros mismos y en nuestros encuentros [31] con otros hombres (STEIN, 2003, p. 590).

A partir dos argumentos apresentados do caminho filosófico escolhido e determinado por Edith Stein na construção de uma antropologia filosófica e teológica que pudesse estruturar a Pedagogia e a Educação em bases seguras e fundamentadas, serão apresentadas as três dimensões do ser humano. O desenvolvimento dessa parte do texto seguirá, por questões epistemológicas e metodológicas, a sequência dada por Edith Stein: corpo, psique e espirito. 


\section{A estruturação da pessoa humana na filosofia de Edith Stein: corpo, psique e espírito}

De acordo com o que foi dito anteriormente, a busca investigativa sobre o ser do ser humano é percebida como o fio condutor de toda a obra de Edith Stein. O caminho filosófico, espiritual e metodológico realizado por Stein fundamenta-se em uma ontologia da pessoa que conceitua o ser humano mediante uma unidade tripartite corpo, psique, espírito, que como já foi salientando anteriormente, Stein a apresenta em três dimensões, no entanto, esclarece no decorrer de todo o texto A Estrutura da Pessoa Humana que a dimensão da natureza quanto a dimensão espiritual do ser do ser humano se convergem e se entrelaçam formando uma unidade. A compreensão dessa unidade tripartite é relevante se compreendida por ser o fundamento da visão educativa de Edith Stein e, com esse intento definido, é necessário entender os diferentes níveis da estrutura do ser humano.

\section{O corpo}

O ser humano para Edith Stein é um corpo material e vivo. Enquanto corpo material que está submetido às observações de quem está diante de seus olhos enquanto um corpo vivo, que tem características físicas e, além disso, assim como as demais coisas, vive sob a égide das leis da natureza material "El material del que parte nuestra investigación acerca del hombre es por lo tanto lo que tenemos ante nuestros ojos en la experiencia viva. Es algo bien variado" (STEIN, 2003, p. 591). É interessante ressaltar como a filósofa Edith Stein argumenta sobre as percepções do corpo material alicerçada na observação externa. Dentre as percepções se pode destacar a que afirma que experimentamos aos outros seres humanos como aqueles que são distintos de nós mesmos. Essa experimentação é externa na medida em que o que se conhece do outro no primeiro momento com quem se depara na experiência é, justamente, aquilo que nos chama a atenção no outro. E o que nos chama a atenção inicial no outro são as suas características materiais, logo, externas:

[...] si son altas o bajas, de tez clara u oscura, etc. La forma, la altura, el color: todas estas son características que posee cualquier cosa material. De hecho, por suconstitución corporal el hombre es una cosa material como cualquier otra, está sometido a las mismas leyes y está inscrito en el marco de la naturaleza material (STEIN, 2003, p. 591). 
Apesar dessa constatação da natureza material do corpo do ser humano, Stein esclarece que o ser humano não pode ser visto tão somente enquanto um corpo material, porque se diferencia de uma simples massa corpórea, por ser um corpo vivo que tem mobilidade, e essa mobilidade o leva de um lugar para outro com autonomia, diferentemente, por exemplo, de uma árvore ou de qualquer outra coisa que não tenha mobilidade. Tem outra característica que distingue o ser humano das outras coisas que também estão submetidas às leis da experiência, que é a sua sensibilidade e, também, pelo fato de ser movido por um organismo.

Pero necesitamos dirigir nuestras miradas de un modo especial para percibirlo con toda claridad. En efecto, en la experiencia natural nunca vemos al hombre solamente como un cuerpo material. Cuando un hombre se mueve, ese vimiento corresponde, sin duda, a la imagen que tenemos de él. Pero si una piedra o una figura de cera empezasen a moverse sin un impulso exterior, nos horrorizaríamos. En el primer caso habíamos captado de antemano algo vivo, em el segundo algo "muerto", y es propio de lo vivo poder moverse por sí mismo. El hombre es por tanto un cuerpo material, y es algo vivo (STEIN, 2003, p. 591).

A sensibilidade enquanto uma característica do corpo vivo a que se refere Stein, de acordo com Alfieri (2014), não se limita que tão somente as percepções internas que temos do nosso corpo ao tocá-lo, pois ocorre "[...] uma dupla sensação tátil” (ALFIERI, 2014, p. 65), pois temos tanto as percepções sensoriais quanto "[...] as afecções da dimensão psíquica" (ALFIERI, 2014, p. 65).

\section{A psique}

A segunda dimensão da estrutura do ser humano diz respeito à experiência psíquica. $\mathrm{O}$ ser humano tem um corpo vivente, justamente porque tem matéria e tem psique. Segundo Sberga (2014, p. 117) “[...] A vida psíquica aproxima o mundo animal do mundo humano". Nesse sentido, ser humano não só tem estímulo, porém, tem também percepção, esta última, é considerada por Stein como a primeira atividade intelectual do ser humano. Essa atividade intelectual é o que diferencia o ser humano das plantas e dos animais, porque através da mesma, o ser humano percebe claramente e de forma profunda que existe seu corpo, sua psique e o seu espirito. E, assim, experimenta a sua corporeidade, porque sente todos os membros do seu corpo e, assim, tem consciência de que é o seu lhe pertence, além disso, pode sentir os seus medos, suas alegrias, seus gostos, seus sofrimentos e pode atingir a 
compreensão dessas percepções mais profundas. Também através da sua psique toma decisões diante de qualquer circunstância em que se encontre e pode exercer a sua plena liberdade em fazer ou não determinadas coisas.

\begin{abstract}
Cuando miro a un hombre a los ojos, su mirada me responde. Me deja penetrar en su interior, o bien me rechaza. Es señor de su alma, y puede abrir y cerrar sus puertas. Puede salir de sí mismo y entrar en las cosas. Cuando dos hombres se miran, están frente a frente un yo y outro yo. Puede tratarse de un encuentro a la puerta o de un encuentro em el interior. Si se trata de un encuentro en el interior, el otro yo es un tú. La mirada del hombre habla. Un yo dueñode sí mismo y despierto me mira desde esos ojos. Solemos decir también: una persona libre y espiritual. Ser persona quiere decir ser libre y espiritual. Que el hombre es persona: esto es lo que lo distingue de todos los seres de la naturaliza (STEIN, 2003, p. 648).
\end{abstract}

Stein esclarece, nessa citação, que o ser humano se distingue de todos os seres da natureza, pois se pode identificar nele uma causa interna que o permite não ser totalmente submisso às circunstâncias nas quais se encontra inserido, pois na sua psique além das qualidades psíquicas como a sensação, a emoção, a estimativa e o estado de ânimo, se encontra na psique outras qualidades que se somam e, assim, complementam a sua unidade. Depois de analisar a dimensão do corpo e da psique, será abordada a última dimensão da estrutura do ser humano que é o espirito.

\title{
O espírito
}

O espírito é a dimensão da estrutura humana que possibilita a expressão da liberdade na medida em que tem uma psique. A sua dimensão espiritual do ser humano o permite por na natureza algo de bem ou de mal. Diferentemente das plantas e dos animais, estritamente o ente humano tem o essa dimensão espiritual. O homem pode escolher ser perverso ou bondoso diferentemente do animal é tão somente selvagem. O espírito é o que fundamenta as possiblidades do homem fazer as suas escolhas e a refletir sobre o sentido das mesmas. Na sua composição harmônica, essa dimensão estabelece a composição harmônica entre a dimensão do corpo e da psique.

La relevancia del alma para la estructura de la persona humana, concebida esta última como un ser en el que el espíritu y el 'material' se interpenetran de un modo muy específico, nos servía más arriba para establecer una contraposición entre la persona humana y otros seres personales-espirituales. Querría ahora mostrar otra característica propia del alma que la caracteriza 
como un ser peculiar ya dentro del ámbito de lo espiritual (STEIN, 2003, p. 706).

Dessa forma, o espirito diz respeito ao que é especificamente humano e, por isso, não pode ser encontrado em nenhum outro ser que existe na humanidade. $\mathrm{O}$ espírito nesse sentido segundo Sberga (2014, p.121) "Spiritus indica algo da alma, ou seja, que o ser humano tem algo em si que não é o corpo e que se aproxima de outras realidades, como a de Deus, que é o Espírito por excelência, ou dos anjos, que são espíritos puros finitos”.

É relevante salientar que o espírito (geist) para Stein significa a "abertura para algo", ou seja, esse algo se refere tanto em relação ao mundo objetivo das coisas da natureza quanto ao mundo subjetivo dos outros seres humanos (vivência empática) ou do Ser divino. O espírito que possibilita ao ser humano estabelecer o ato comunicativo com os outros seres humanos, através do ato de conhecer, amar e também transcender a si mesmo, também possibilita a experiência em forma de vivencia do seu corpo da sua psique.

\section{Pistas das contribuições filosóficas steinianas para se repensar o caminho da formação filosófica e acadêmica do professor de filosofia}

Os argumentos referidos acima acerca da problematização e explanação da natureza do ser humano e da metodologia adequada a sua compreensão, na realidade, é um aporte teórico e metodológico que pode ser apreendido pelos educadores e educadoras, a partir de análises sólidas, como pistas para fundamentar qualquer discussão sobre a formação acadêmica na área de filosofia e as demais. Edith Stein faz uma importante ressalva que qualquer discussão sobre a formação humana que não atinja o seu cerne, o que irá promover é tão somente uma discussão supérflua por manter-se nas periferias da existência do ser humano. Por isso, a filósofa no capítulo II do livro A Estrutura da Pessoa Humana inicia a sua escrita com uma profunda advertência para toda docente e todo docente que se encontra em plena atividade de ensino e pesquisa nos institutos de formação acadêmica:

[...] Si la ideia del hombre es de relevância decisiva tanto para la estrutura de la pedagogia como para la labor educativa, será de urgente necessidade para estas ultimas gozar de um firme apoyo em esa ideia. La pedagogia que carezca de respuesta a la pergunta '? qué es el hombre?' no hará sino construir castillos em el aire ( STEIN, 2003, p. 579).

As afirmações de Edith Stein nessa citação oferecem uma excelente pista do ponto de 
partida da sua busca filosófica para a estruturação de um projeto pedagógico de formação na área de filosofia que não se alicerce nos rastros dos caminhos de uma pedagogia procedimental, a qual nos fala Jean- François Mattéi. A pedagogia procedimental de acordo com o autor promove uma verdadeira inversão pedagógica no processo educativo por enaltecer e valorizar os procedimentos mecânicos em detrimento da discussão sobre a constituição do ser humano em sua humanidade, resultando assim, numa inversão que resulta no coroamento de práticas pedagógicas, pois:

[...] já não situa o saber nos conteúdos substanciais a ensinar ao aluno, mas nos métodos formais que se fecham em seus próprios procedimentos. É o que ocorre hoje com a PPO, ou Pedagogia Por Objetivos, cujo projeto já se encontra desconsiderado pela sigla, que depende, como toda sigla, de um processo de etiquetagem e não de uma reflexão criadora de sentido (MATTÉI, 2002, p. 192-193).

A discussão de Mattéi sobre a barbárie da educação no seio da Era Moderna proporciona pensar numa possível aproximação com o pensamento de Edith Stein na medida em que se percebe nas reflexões de ambos um ponto comum: que é a denúncia de que o processo pedagógico da formação humana na educação moderna não tem como objetivo constituir o ser humano, porém dissolvê-lo e, devido a essa postura, a pergunta sobre o que é ser humano não é vista como relevante para fundamentar a ciência da educação. As críticas de Mattéi corroboram com as ideias de Edith justamente por elegerem como ponto de partida das suas reflexões acerca da educação moderna a constatação que no interior da mesma, se encontra instalada a falta de sentido da dimensão humana das práticas educativas por não terem levado em consideração uma investigação prévia sobre o ser humano enquanto tema primordial e antecedente a sua constituição, instaurando assim a crise na educação. Essa crítica da falta de sentido das práticas educativas no interior da Educação na perspectiva de Edith Stein está intrinsecamente relacionada com a sua denúncia acerca da superficialidade do sistema educativo enquanto aquela que provém da crise do sistema educacional "Todo nuestro sistema educativo se encuentra desde hace años em uma situción de crisis" (STEIN, 2003, p. 196). A crise resulta do fato de que educação alemã deu mais ênfase a um tipo de formação alicerçada na posse de conhecimento em detrimento de uma investigação prévia sobre a estrutura da pessoa humana, a qual é a que possibilita que a personalidade humana assuma sua própria forma. E, assim, mediante essa crise, Stein assume a missão de reestruturação da educação alemã. Essa denúncia sobre a crise dos 
sistemas de ensino alemão faz parte de seu pronunciamento na conferência destina a comissão de formação da associação das mulheres católicas alemãs, em Bendorf em Rheim, no dia 8 de novembro de 1930. Partindo dessa crítica é pertinente a observação de Éric de Rus de que a pergunta sobre "O Que é o ser humano?” no contexto do pensamento filosófico de Edith Stein é o que: "[...] constitui o eixo que permite uma decifração da obra steiniana" (RUS, 2015, p. 26).

Edith Stein ao assumir essa missão de reestruturação da educação alemã e, a partir do eixo da sua investigação filosófica acerca da pergunta sobre o que é o ser humano? fez uma averiguação inicial da antropologia alicerçada nas Ciências Naturais como foi mostrado anteriormente, e se depara no âmbito desta, com uma discussão científica sobre o ser humano entende-o tão somente como espécie, tal como é praticado pela zoologia. Dessa forma, no processo dessa investigação acerca da antropologia que segue esse víeis da ciência natural por se basear estritamente pelo mundo material e as suas leis universais, Stein, constata a sua insuficiência para tratar da individualidade do homem. Essa insuficiência, é apresentada pela filósofa a partir de dois pontos cruciais da sua crítica a essa antropologia, no primeiro faz a seguinte alusão:

Dado que la formación y la educación han de abarcar al hombre entero, tanto a su cuerpo como a su alma, es importante para el educador conocer la estructura, las funciones y las leyes evolutivas del cuerpo humano. Sólo así podrá saber qué puede fomentar su desarrollo natural y qué puede perjudicarlo. Es asimismo importante conocer las leyes generales de la vida anímica del hombre, a fin de [3] tenerlas en cuenta en la labor educativa (STEIN, Edith, p. 580, 2003).

O segundo ponto da sua crítica consiste na sua observação que o ser humano é um ser social, membro de grupos suprapessoais, e, assim, também é tarefa do educador conhecer as estruturas supraindividuais, tais como: os povos e as raças das quais o indivíduo é exemplar, e formá-lo não apenas enquanto indivíduos, mas também como membros do todo, dessa forma, faz a seguinte observação:

También el conocimiento de los grupos humanos, de los pueblos, etc. en sus respectivos modos de ser propios es de gran relevancia pedagógica. Por un lado, debido a que los individuos son ejemplares de esos tipos, por lo que el conocimiento de éstos constituye un buen instrumento para comprender a aquéllos. Un segundo motivo es que cada hombre concreto no es un individuo aislado, sino que es miembro de grupos suprapersonales, como el pueblo y la raza, y es misión del educador formarle no sólo como individuo, sino también como miembro del todo ( STEIN, p. 580, 2003). 
Edith Stein alicerçada na percepção dessa insuficiência da concepção antropológica acima ressaltada busca, mediante uma investigação rigorosa, de acordo com Mariana Bar Kusano (KUSANO, 2014, p.67) “[...] nas ciências do espirito um modelo que dê conta da estrutura humana em todas as suas dimensões, de sua individualidade e que ofereça critérios para atividade que tenha relação com estruturas supraindividuais como a raça e a humanidade." Essa busca por uma antropologia filosófica que sirva de fundamento da pedagogia e da prática educativa, a filósofa a efetiva mediante a apresentação de dois pontos de vistas muito interessantes para se pensar a formação docente em seus aspectos filosóficos e pedagógicos não só na área de filosofia como também nas demais, alicerçada nos seguintes pontos, citando Stein:

El educador se ocupa de individuos humanos. En la medida em que son ejemplares de un tipo, el conocimiento de este último puede ayudarle a comprender [5] a los individuos. Pero ser ejemplar de un tipo nunca implica ser derivable y explicable por completo a partir del mismo. En efecto, los tipos no se pueden determinar con exactitud matemática. Sus ejemplares no guardan con ellos la misma correspondência que las copias con el cliché, sino que encarnan el tipo con mayor o menor pureza. Ni siquiera la más pura encarnación del tipo es un mero ejemplar del mismo, sino que lo muestra en una caracterización individual. Por ello, siempre que se pretenda comprender al individuo exclusivamente desde el tipo, será inevitable malinterpretarlo. Constituiría también una peligrosa fractura de la unidad del acto pedagógico que el educador no centrase su atención directamente en el educando, sino que por así decir sus miradas estuviesen en un continuo ir y venir entre él y un esquema general. Para el educando, que percibe esta fractura $\mathrm{Y}$ que sin embargo quisiera verse como término de una relación directa, de una relación con él como individuo, como este hombre con su irrepetible modo de ser propio, y no como ejemplar de un tipo, esa actitud del educador sería un motivo para cerrarse y para sustraerse tanto a la mirada del educador que trata de comprenderle como a los intentos de éste por influir en él (STEIN, 2003, p. 580).

Nesse primeiro ponto é relevante para se pensar a formação docente de filosofia está condizente como a sua finalidade, pois a filósofa adverte que é imprescindível que o educador busque na sua atuação teórica e prática atentar para a compreensão e reconhecimento da individualidade única do educando durante o seu processo de formação na medida em que, é pertinente atentar filosófica e pedagogicamente para essa dupla relação entre o universal e o particular do ser humano enquanto um pressuposto teórico da atividade pedagógica. Essa compreensão do educador em perceber a singularidade do outro (educando) evita a cisão da unidade do ato pedagógico. Essa cisão consiste no fato do educador não ter 
como foco a visão individual de cada educando e, assim, na realidade, sem esta, não o permitirá compreender a sua essência enquanto um ser livre que é capaz de construir durante o processo formativo os aspectos significativos da sua individualidade. Francesco Alfieri ao elaborar a sua reflexão acerca do conceito de singularidade no pensamento de Stein faz menção o mesmo:

O ser singular não se distingue de modo algum conteúdo quando comparado a outro ser singular. Na pessoa humana, encontramos características (tipos de conteúdo) que são compartilhados por todos os seres de sua espécie (universal); porém; cada indivíduo reúne conteúdos de modo inteiramente singular, por sua maneira individual de realiza-lo. (ALFIERI, 2014, p.58).

O conceito de singularidade remete ao conceito de liberdade no pensamento de Edith Stein. A liberdade, segundo Alfieri (p. 110, 2014), em Stein significa: "[...] que quando a pessoa tem consciência de quem é, ela é livre para sair de si e viver no mundo [...]”. Nesse sentido, o mundo se refere não só as pessoas, mas também as coisas, de tudo, pois ter consciência de si possibilita viver plenamente a liberdade. A vivência da liberdade na perspectiva de Stein tem sempre o outro diante de si, como valor. Nesse sentido, a liberdade em Stein nunca é vivenciada isolada do outro, pois não existe liberdade só minha. A liberdade pessoal que eu tenho é aquela que eu tenho que ir em direção a outrem e, então, aderir plenamente às outras singularidades. Nesse sentido, a liberdade compreendida por Stein é aquela que possibilita viver de maneira nova. E o que isso significa? Significa que a liberdade possibilita utilizar tudo o que se tem sob uma nova perspectiva.

El hecho de que existen razas y pueblos, y de que cada hombre concreto pertenece a alguno de ellos, confronta al pedagogo con la pregunta de cómo debe actuar ante ese hecho. Es decir, ha de preguntarse si la educación tiene obligaciones no sólo hacia el individuo, sino también hacia esas unidades suprapersonales, y qué importancia poseen estas últimas para el individuo y para toda la humanidad. Todas estas son preguntas a las que una antropología que proceda conforme al método de la ciencia natural no puede responder. Pues para decidir qué atención merecen elindividuo, la raza y la humanidad en sus relaciones mutuas, es preciso un criterio valorativo. Pero en la ciencia natural no existe, por lo que ésta resulta irrelevante para señalar objetivos pedagógicos (STEIN, 2003, p. 580).

Nesse segundo ponto, se percebe a preocupação de Stein que o educador precisa atentar para o fato que os seus educandos dentro de um contexto social, ou seja, é relevante que compreenda que a estrutura do ser humana também está perpassada pelo seu ser social. 
Nesse sentido o educando precisa ser compreendo pelo educador a partir de uma dinâmica de relações, estruturas e tipos sociais, que apontam para um individuo imerso numa coletividade e coodeterminado em todo seu corporal-anímico. Stein parte do principio de que estudar o individuo humano isolado é uma pura abstração, pois a vida em comum não se dá apenas por uma razão genética, mas, por pertencer à própria condição humana “[...] El individuo humano aislado es una abstracción. Su existencia es existencia en un mundo, su vida es vida en común (STEIN, 2003, p. 713)” . A Antropologia Filosófica e Teológica de Edith Stein são fecundas para germinar uma apreciação da estruturação da formação docente em filosofia nas universidades públicas em nosso país.

\section{Considerações finais}

As considerações finais ainda são parciais em relação ao tema proposto e as mesmas consistem na constatação sobre a relevância da contribuição significativa da Antropologia Filosófica e Teológica de Edith Stein como uma ferramenta teórica para problematizar na contemporaneidade as lacunas do processo de formação docente do professor de filosofia que refletem de forma preponderante na qualidade do ensino de filosofia no ensino médio.

As questões pedagógicas elaboradas por Stein, apresentados por Sberga, demarcam a importância que a filósofa-educadora oferece uma preparação para a docência alicerçada num conhecimento profundo sobre a estrutura universal do homem. Seguindo a linha de raciocínio de Edith Stein, se percebeu a necessidade e as possibilidades de encontrar as pistas para problematizar criticamente o processo de formação filosófica e pedagógica nos bancos das universidades, uma vez que, se constatou lacunas abissais no decorrer da formação docente na área de Filosofia.

Essas lacunas nas condições formativas que estão intrinsecamente relacionadas à tradição acadêmica francesa que alicerçou o modelo uspiano. Esse modelo serviu de referência em todo Brasil de institucionalização dos cursos universitários brasileiros. O modelo de institucionalização uspiana assumiu a seguinte caraterística de acordo Tomazetti (2012, p.91) " [...] caracteriza-se pela ênfase na História da Filosofia e na leitura e interpretação de textos clássicos". Mediante essas condições, os cursos de licenciatura em Filosofia, por sofrer as influências do modelo uspiano, têm as suas grades curriculares demarcadas pela classificação de grandes períodos, das escolas e dos temas que têm uma relação intrínseca com tais períodos. 
Essa postura bipartiu a formação universitária nos cursos de filosofia em duas grandes áreas: a do bacharel e a do professor, ou seja, o curso de filosofia é um modelo dicotomizado por dois tipos de formação que não fazem parte nem do mesmo departamento. As disciplinas referentes à formação dos conteúdos específicos ficam a cargo do departamento de filosofia e as disciplinas referentes à formação do professor a cargo do departamento de Educação. Esse hiato estabelecido entre o bacharel e o professor de filosofia enfraquece a importante discussão sobre o sentido do ensino de filosofia no ensino médio e da formação inicial e continuada do professor de filosofia enquanto temas pertinentes e relevantes para o pensamento filosófico. Entretanto, é necessário destituir e superar essa barreira entre o bacharelado e a licenciatura mediante uma discussão ampliada sobre a construção de um novo modelo de formação filosófica e pedagógica, alicerçada numa reflexão filosófica sobre a formação humana fundamentada numa ideia de homem integral, ou seja, nas suas dimensões: corporal-psíquica-espiritual-social, para que a teoria e a prática docente na área de filosofia possibilitem, aos educandos que se encontram nas escolas do ensino médio, possam se desenvolver plenamente enquanto seres humanos sem as amarras de uma educação castradora e limitadora das suas infinitas possibilidades de autotransformação, e assim, possam vivenciar no processo educativo a sua liberdade plena enquanto ser humano.

\section{Referências bibliográficas}

ALFIERI, Francesco. Pessoa humana e singularidade em Edith Stein: uma nova fundação da antropologia filosófica. São Paulo: Perspectiva, 2014.

SBERGA, Adair Aparecida. A formação da pessoa em Edith Stein: um percurso de conhecimentp do núcleo interior. São Paulo: Paulus, 2014. (Coleção fillosofia em questão).

RUS, Éric de. Visão educativa de Edith Stein: aproximação a um Gesto Antropológico Integral. Tradução Isabelle Sanchis et al. Revisão Técnica: Juvenal Savian Filho. Belo Horizonte: Editora Artesã, 2015.

STEIN, Edith. Estrutura de la persona humana. In: Obras completas: Escritos Antropológicos y pedagógicos. V. 4. Madri/Burgos:Vitória Ediciones El Carmen/Editorial de Espiritualidad e Editorial Monte Carmelo, 2003.

TOMAZETTI, Elisete Medianeira et.al. Pesquisa sobre o ensino da filosofia e formação docente: percursos e inclusões. IN: Instigar a pensar e a questionar: o sentido do ensino de filosofia. Campinas, SP: Mercado de Letras, 2012. (Série educação geral educação superior e formação continuada do educador)

MATTÉI, Jean- François. A barbárie interior: ensaio sobre o i-mundo moderno. Tradução Isabel Maria Loureiro. São Paulo: Editora UNESP, 2002.

KUSANO, Mariana Bar. A antropologia de Edth Stein: entre Deus e a filosofia. São Paulo: Ideias e Letras, 2014. 